\title{
Removable partial dentures: an introduction
}

\section{J. C. Davenport, ' R. M. Basker, ${ }^{2}$ J. R. Heath, ${ }^{3}$ J. P. Ralph, ${ }^{4}$ and P-O. Glantz, ${ }^{5}$}

$\mathrm{T}$ his series of articles has been selected from two new publications replacing 'A Colour Atlas of Removable Partial Dentures', Davenport, Basker, Heath and Ralph, Wolfe Medical Publications Ltd, 1988. The content has been much revised and augmented, and has been reorganised into two volumes to conform to the format of the successful 'Clinical Guide' series of the BDJ. The first volume, 'A Clinical Guide to Removable Partial Dentures' focuses on the clinical aspects and techniques of removable partial denture (RPD) treatment, while the second volume, 'A Clinical Guide to Removable Partial Denture Design' concentrates on the procedures and principles of designing RPDs.

The series of articles commencing in this issue of the BDJ comprises a selection from both volumes. As it is not possible within the series to include more than a fraction of the books' contents the topics have been chosen to give a coherent account of those aspects leading up to the provision of definitive RPD treatment, namely:

1. Need and demand for treatment, including a consideration of RPDs and the elderly

2. The removable partial denture equation of risk versus benefit

3. Communication between the dentist and the dental technician

4. Surveying

5. A system of design

6. Retention

7. Bracing and reciprocation

8. Principles of clasp design

9. Indirect retention

10. Connectors

11. Initial prosthetic treatment

12. Tooth preparation

There is still limited scientific data on which to base current concepts of RPD design. However, there is a widely held view amongst prosthetic specialists that hygienic aspects of RPD design are of overriding importance compared with those design aspects concerned primarily with mechanical requirements. It is the authors' intention that this series of articles should clearly reflect this belief in the importance of basing RPD design predominantly on the need to maintain the oral health of the patient.

\footnotetext{
$1^{*}$ Emeritus Professor, University of Birmingham, UK ; ${ }^{2}$ Professor of Dental Prosthetics, University of Leeds and Consultant in Restorative Dentistry, Leeds Teaching Hospitals NHS Trust, Leeds, UK; ${ }^{3}$ Honorary Research Fellow, University of Manchester (Formerly Senior Lecturer in Restorative Dentistry, University of Manchester) and Consultant in Restorative Dentistry, Central Manchester Healthcare Trust, Manchester, UK; ${ }^{4}$ Consultant in Restorative Dentistry, Leeds Teaching Hospitals NHS Trust and Senior Clinical Lecturer, University of Leeds and Honorary Visiting Professor, Centre for Dental Services Studies, University of York, York, UK; ${ }^{5}$ Professor of Prosthetic Dentistry, Consultant in Prosthetic Dentistry, Faculty of Odontology, University of Malmo, Sweden

${ }^{*}$ Correspondence to: 5 Victoria Road, Harborne, Birmingham B17 OAG email: john.davenport@btclick.com

REFEREED PAPER

(C) British Dental Journal 2000; 189: 363
}

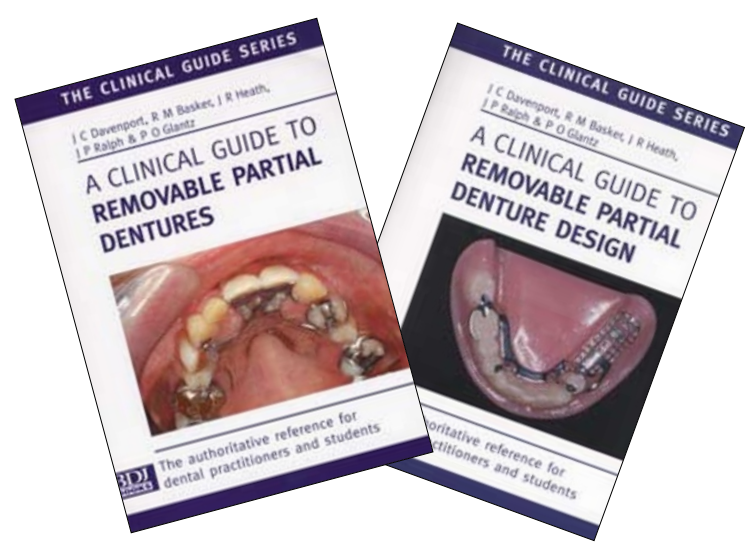

The first article emphasises the important distinction between the need and demand for RPD treatment. The dangers of overtreatment are discussed and the management options for the partially dentate patient considered. A discussion of RPDs and the elderly includes comments on the demographic processes within the population and the possible significance of the retention of at least some teeth into old age.

Effective communication between dentist and dental technician is a cornerstone of competent RPD treatment, so present shortcomings and how they may be overcome will be discussed. Although not included in this series of articles, each of the chapters on the clinical stages of RPD treatment in the first volume conclude with checklists of instructions to the dental technician as an aide mémoire for the dentist.

The process of surveying is described and the reader is taken through a logical sequence for developing the final design.

There will be several articles on various aspects of RPD design. One of these, on clasp design, is taken from a comprehensive section on the principles of design in 'A Clinical Guide to Removable Partial Denture Design'. This section was developed from a collection of design rules produced for a computerised knowledge-based system ${ }^{1}$ for the design of RPDs. This collection of rules was obtained initially from the literature and was subsequently modified in the light of comments received from prosthodontic specialists in all the dental schools in the UK and the Republic of Ireland. The level of support each design rule received from these experts is included as a guide to the reader. Since then further significant contributions to this knowledge base have been made by a number of prosthodontic specialists from several different countries. Their comments have been taken into account in the discussion that follows each rule. Readers are invited to use this article in an interactive way by first forming their own opinion on the design principles listed at the beginning of the article and then comparing their opinions with those of the experts, and considering the points raised in the discussions. We hope that the wealth of prosthodontic knowledge and experience that this section represents will make it of particular and lasting value to the reader.

The series concludes by describing procedures for creating the best possible oral environment for the provision of RPDs.

1 'RaPiD', TMS Ltd, Aylesbury, UK. 